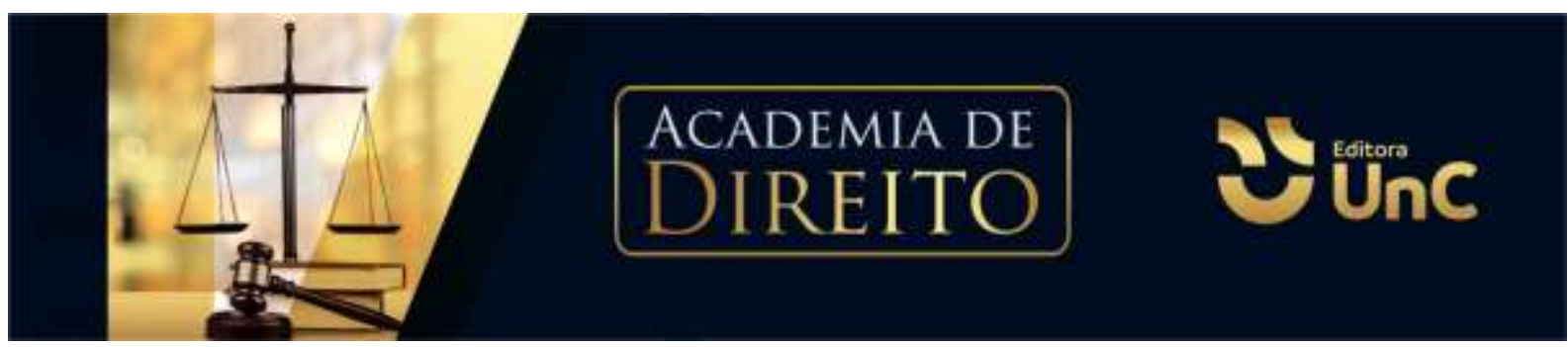

\title{
A EFETIVIDADE DO DIREITO DO CONSUMIDOR FACE À ERROS CRASSOS NO PREÇO DE PRODUTOS/SERVIÇOS
}

\section{THE EFFECTIVENESS OF CONSUMER LAW FACE CROSS ERRORS IN THE PRICE OF PRODUCTS / SERVICES}

\author{
Rayane Koch ${ }^{1}$ \\ Vlademir Vilanova Moreira ${ }^{2}$
}

\begin{abstract}
RESUMO
O artigo versa sobre a efetividade do direito do consumidor face às ofertas que são veiculadas com erro grosseiro no preço dos produtos ou serviços. Neste sentido, a pesquisa discorre a respeito do direito do consumidor, das relações de consumo, e se a oferta deve ou não ser cumprida em favor do consumidor da mesma forma como foi publicada, mesmo que dotada de erro. Na pesquisa, foi adotado o caráter dogmático instrumental, que buscou analisar dados através de ampla pesquisa bibliográfica, além da legislação consumerista, sendo apontados os principais dispositivos legais acerca do tema, assim como os princípios norteadores do Código de Defesa do Consumidor. Foi realizada abrangente análise de jurisprudências, com o intuito de averiguar o entendimento dos Tribunais de Justiça sobre o problema, foi observado que não há entendimento predominante a favor ou contra a pretensão do consumidor. Destarte, pode-se notar que para elucidar o tema é necessário analisar o caso em concreto, tendo como norte os princípios de defesa ao consumidor, principalmente o princípio da boa-fé e o princípio da vulnerabilidade, acompanhar as decisões e fundamentos dos Tribunais, bem como a legislação pertinente.
\end{abstract}

Palavras-Chave: Consumidor. Oferta. Erro. Vinculação. Boa-fé.

\section{ABSTRACT}

The article deals with the effectiveness of the consumer's right in the face of offers that are conveyed with a gross error in the price of products or services. In this sense, a survey discusses consumer rights, consumer relations, and whether or not an offer should be fulfilled in favor of the consumer in the same way as it was published, even if it is error-free. In the research, the dogmatic instrumental character was adopted, which sought to analyze data through extensive bibliographic research, in addition to

\footnotetext{
${ }^{1}$ Graduação em Direito. Universidade do Contestado - Campus Mafra. Santa Catarina. Brasil. E-mail: rayane koch@hotmail.com

${ }^{2}$ Mestre em Ciência Jurídica pela Univali. Docente da Universidade do Contestado - Campus Mafra. Santa Catarina. Brasil. E-mail: vvmr@uol.com.br
} 
consumer legislation, pointing out the main legal provisions on the subject, as well as the guiding principles of the Consumer Protection Code. An analysis of jurisprudence analysis was carried out, in order to ascertain the understanding of the Courts of Justice on the problem, it was observed that there is no predominant knowledge for or against the consumer's claim. Thus, it can be noted that in order to elucidate the issue, it is necessary to analyze the specific case, having as a guideline the principles of consumer protection, mainly the principle of good faith and the principle of vulnerability, monitoring as decisions and grounds of the courts, as well as the relevant legislation.

Keywords: Consumer. Offer. Error. Linking. Good faith.

\section{INTRODUÇÃO}

A pesquisa objetiva explorar a efetividade do direito do consumidor quanto ao erro crasso no preço de produtos ou serviços. A expressão 'erro crasso', no dicionário online de português (2020), significa a ação ou consequência de errar, de se enganar ou de se equivocar.

À vista disso, quando o indivíduo se depara com um produto ou serviço com preço menor que o de costume, e pretende realizar a compra de tal produto ou adquirir o serviço, ou ainda, após a realização desta compra, lhe é informado pelo fornecedor que o preço exposto está equivocado, ao passo que não poderá adquirir o produto da forma como a qual foi publicada, o consumidor sente-se lesado, e busca a tutela jurisdicional para obter seu direito de consumo efetivado.

Nesse sentido, a pesquisa busca constatar a violação ou não do direito do sujeito vulnerável, caso a oferta não seja cumprida da forma como foi publicada, haja vista que por diversas vezes o consumidor sente-se prejudicado pelo fornecedor. Posto isto, encontra-se o seguinte problema: Quando munida de erro, o consumidor deve ter direito a uma oferta da forma como a qual foi veiculada? Trata-se de uma problemática árdua a ser respondida, todavia, será abordada durante o trabalho.

O método de abordagem utilizado na pesquisa foi o dedutivo, e o método de procedimento o comparativo. A técnica de pesquisa foi bibliográfica, através de doutrinas, artigos, legislação, jurisprudências dos Tribunais de Justiça, podendo ser desenvolvido amplo fundamento teórico.

No decorrer do artigo, realizou-se uma abordagem conceitual a respeito do Código de Defesa do Consumidor, quanto aos elementos objetivos e subjetivos que 
regem as relações de consumo, assim como foi explanado acerca de alguns dos princípios e proteções que devem reger as relações entre o consumidor e o fornecedor. Ademais, foi demonstrado o efeito vinculante da oferta, informação e publicidade, e quais são seus pressupostos. A Lei de defesa ao consumidor é manifesta quanto a vinculação da oferta, pois aduz que independentemente da forma ou meio de divulgação do produto ou serviço, sendo suficientemente precisa, dispõe de força vinculante perante o fornecedor, portanto, em tese, deve o fornecedor cumprir a oferta da forma como a qual ofertou. Na sequência, explanou-se a respeito da oferta munida de erro quanto ao preço do produto ou serviço, e se o fornecedor fica a ela vinculado mesmo dotada de erro crasso. Destarte, foram apontadas decisões dos Tribunais de Justiça, favoráveis e desfavoráveis à pretensão do consumidor.

O tema abordado tange de suma importância, haja vista que diariamente são intentadas diversas demandas na esfera judicial a respeito da problemática, congestionando os Tribunais e, consequentemente, prolongando a efetividade das decisões judiciais como um todo.

Destarte, o assunto explanado no decorrer da pesquisa possui destaque no cenário jurídico brasileiro, eis que não há uma tese firmada a favor ou contra o consumidor lesado, devendo ser observado o caso em concreto.

\section{CÓDIGO DE DEFESA DO CONSUMIDOR}

O consumo está rotineiramente presente na vida do ser humano, seja ao comprar uma bala, seja ao solicitar um reparo no automóvel. Destarte, por ser o consumidor a parte mais vulnerável da relação consumerista, é necessário um mecanismo para promover o equilíbrio nas relações de consumo.

O Direito do Consumidor foi criado em decorrência da evidente superioridade do fornecedor face ao consumidor em suas relações contratuais (THEODORO JUNIOR, 2017).

Benjamin, Bessa e Marques (2017, p. 41), aduzem que:

O chamado direito do consumidor é um ramo novo do direito, disciplina transversal entre o direito privado e o direito público, que visa proteger um sujeito de direitos, o consumidor, em todas as suas relações jurídicas frente ao fornecedor, um profissional, empresário ou comerciante. Este ramo novo 
do direito, que podemos chamar de tutelar (protetório) ou social, foi introduzido nos currículos das faculdades de direito no Brasil apenas no final do século XX, após a Constituição Federal de 1988.

Em decorrência da nova organização da sociedade, o surgimento do Direito do Consumidor foi então determinado, com base principal na hipossuficiência do consumidor nas relações de consumo como um todo. Nas palavras de Theodoro Junior (2017, p. 4), "a função principal do Código é reequilibrar as forças dos sujeitos da relação consumerista, diminuir a vulnerabilidade do consumidor e limitar as práticas nocivas de mercado".

Nunes (2015) aduz, ainda, que o CDC é um subsistema próprio dentro do sistema constitucional, porquanto integra um sistema autônomo dentro do quadro constitucional. A proteção do consumidor é, acima de tudo, um direito fundamental esculpido nos arts. $5^{\circ}$ XXXII, e 170, V, da Constituição Federal de 1988, e cabe ao Estado salvaguardar este direito.

Neste sentido, o Código de Defesa do Consumidor versa sobre as relações de consumo. As relações de consumo são caracterizadas pelos elementos subjetivos e objetivos que a compõe. Os elementos subjetivos dividem-se em: consumidor e fornecedor. Quanto os objetivos, referem-se à prestação em si, dividindo-se em produto e serviço (SOBRAL PINTO; NOGUEIRA, 2016).

Nas palavras de Khouri, (2009, p. 32),

\begin{abstract}
O objetivo do CDC, ao proteger o consumidor, não é a simples proteção pela proteção em si, mas a busca permanente do equilíbrio do contrato entre o consumidor e o fornecedor de bens e serviços. Este, em princípio, o mais forte economicamente, e em condições de impor sua vontade, num ambiente propicio à conquista de maior vantagem econômica contra aquele reconhecidamente vulnerável, o mais fraco da relação. O CDC nada mais é do que uma tentativa de reequilibrar essa relação, tendo em vista a posição econômica favorável do fornecedor; impondo-se a necessidade de um equilíbrio mínimo em todas as relações contratuais de consumo.
\end{abstract}

Outrossim, consubstanciado ao entendimento de Tartuce (2020), para esclarecer a incidência da Lei de Defesa do Consumidor, é necessário estudar a estrutura das relações jurídicas do consumidor sob a ótica de seus fatores objetivos e subjetivos, ou seja, as partes relacionadas e seu conteúdo. 


\title{
2.1 CONCEITO DE CONSUMIDOR
}

Consumidor é toda pessoa física e jurídica que adquire ou utiliza determinado produto ou serviço para seu consumo, isto é, para que seja considerado consumidor, o indivíduo deve ser o destinatário final do produto ou serviço adquirido. Nunes, (2015), afirma que consumidor é a pessoa física, a pessoa natural e a pessoa jurídica. Como a norma não faz distinção quanto a pessoa jurídica, refere-se a toda e qualquer pessoa jurídica, quer seja uma multinacional, uma microempresa, pessoa jurídica comercial ou civil, associação, e demais denominações.

Existem três teorias acerca da definição de consumidor, a maximalista, que acresce a noção de consumidor, a finalista, tratando-se de uma teoria mais restritiva, e ainda, a teoria do finalismo aprofundado, a qual se coloca numa condição intermediária diante daquelas já citadas.

\begin{abstract}
A teoria finalista restringe a conceituação de consumidor, para abarcar apenas o não profissional, seja ele pessoa física ou jurídica. [...] Para os finalistas, o destinatário final a que a lei faz referência é aquele que retira o bem do mercado, dando-lhe uma destinação pessoal, sem qualquer interesse profissional. Trata-se de uma conceituação fática e econômica. Já os maximalistas entendem o CDC como um Código geral sobre o consumo, aplicável a todos os agentes do mercado, os quais podem assumir os papeis ora de fornecedores, ora de consumidores (THEODORO JUNIOR, 2017, p. $6-7)$.
\end{abstract}

Diante das teorias apontadas, pode-se notar que a teoria maximalista estende a noção de consumidor, e adota um critério tão somente objetivo. De outra parte, a teoria do finalismo aprofundado ampliou a teoria finalista, haja vista que, de acordo com tal teoria, há a presunção de vulnerabilidade, ou seja, hipossuficiência do consumidor, e que isto justificaria, de forma excepcional, a ampliação da proteção legal também às atividades empresariais.

Nunes (2015), acrescenta ainda que o conceito de consumidor adotado pelo CDC, trata-se do sujeito que no mercado de consumo adquire bens ou contrata serviços, como destinatário final, ou seja, exclusivamente de caráter econômico.

A atual posição do Superior Tribunal de Justiça faz uso da teoria finalista aprofundada. "Em certos casos, o STJ busca abrandar o critério subjetivo aplicado pela lei desde que presente a vulnerabilidade, que é a principal característica do 
consumidor. Ocorre desse modo a denominada Teoria Finalista Aprofundada". (SOBRAL PINTO; NOGUEIRA, 2016, p. 22).

Nessa linha, Khouri (2009, p. 34), entende que "não basta que o cidadão retire o produto do mercado, importa que ele o utilize como destinatário final", ou seja, o mercador que adquire um produto para revenda não pode ser considerado consumidor, tratando-se neste caso de um intermediário, e não um destinatário final.

\subsection{CONCEITO DE FORNECEDOR}

Fornecedor é, consoante ao artigo $3^{\circ}$ do CDC, toda pessoa física ou jurídica, pública ou privada, nacional ou estrangeira, assim como os entes despersonalizados, que desenvolvem atividade de produção, construção, importação, montagem, criação, exportação, distribuição ou comercialização de produtos ou prestação de serviços. Destarte, podem ser fornecedores prestadoras de serviços, indústrias e comércio em geral. Segundo Benjamin, Bessa e Marques (2017), a definição de fornecedor é relacional, dependendo da existência de um consumidor no outro lado da relação jurídica, seja esta relação extracontratual ou contratual. À vista disso, a definição de fornecedor é bastante ampla no CDC.

Theodoro Junior (2017) alega que o critério para definição de fornecedor é desenvolver práticas tipicamente profissionais, apontando também a necessidade de certa habitualidade, como a distribuição, bem como transformação de produtos.

Além disso, para idealizar o conceito de fornecedor, o Código Civil de 2002, em seu art. 966, estabelece a caracterização de empresário, "considera-se empresário quem exerce profissionalmente atividade econômica organizada para a produção ou a circulação de bens ou de serviços" (TARTUCE, 2020, p. 65). Conforme o entendimento de Nunes (2015), fornecedor é gênero do qual fabricante, importador, produtor e comerciante são espécies. E, quando a lei de proteção ao consumidor quer que todos sejam obrigados e/ou responsabilizados, usa-se o termo fornecedor.

\subsection{CONCEITO DE PRODUTO E SERVIÇO}

O Código de Defesa do Consumidor traz, em seu art. $3^{\circ}$, parágrafo $\S^{\circ} \mathrm{e} 2^{\circ}, \mathrm{o}$ conceito de serviços como "abrangendo as atividades remuneradas oferecidas no 
mercado de consumo, e os produtos, que correspondem aos demais bens postos em circulação" (PAIVA, 2014, p. 2).

Art. $3^{\circ}[\ldots] \S 1^{\circ}$ Produto é qualquer bem, móvel ou imóvel, material ou imaterial.

$\S 2^{\circ}$ Serviço é qualquer atividade fornecida no mercado de consumo, mediante remuneração, inclusive as de natureza bancária, financeira, de crédito e securitária, salvo as decorrentes das relações de caráter trabalhista (BRASIL, 1990).

Outrossim, para distinguir se o objeto da relação de consumo é um serviço ou um produto, deve ser verificado o núcleo do vínculo obrigacional entre fornecedor e consumidor. Ora, se versa sobre uma obrigação de fazer, será serviço, e, tratando-se de obrigação de dar, será produto.

Paiva, (2014, p. 2), apresenta seu ponto de vista a respeito de serviços, e afirma que "o principal elemento caracterizador de uma prestação de serviço de consumo é a sua remuneração. É preciso que haja uma contraprestação economicamente valorativo para que seja possível a formação de uma relação de consumo".

Por derradeiro, é certo que para caracterização da relação de consumo, é indispensável a presença dos elementos subjetivos (consumidor e fornecedor) e pelo menos um dos elementos objetivos (produto ou serviço).

\section{PRINCÍPIOS DA LEI N. 8.078/90}

Através dos princípios e dos direitos básicos conferidos a parte consumidora, o Código de Defesa do Consumidor pretende obter o equilíbrio contratual, promovendo uma política mais favorável ao consumidor. Ademais, como todo microssistema legislativo, o Código de Defesa do Consumidor traz conceitos, princípios e regras que devem ser empregados sempre na busca da defesa do consumidor (REIS FINKELSTEIN; SACCO NETO, 2010).

Tem-se dito que se a Lei n. 8.078/90 tivesse limitado a seus primeiros sete artigos, ainda assim o consumidor poderia receber uma ampla proteção, pois eles refletem concretamente os princípios constitucionais de proteção ao consumidor e bastaria aos intérpretes compreender seus significados. Isso é verdade e mais: ver-se-á que as normas posteriormente estipuladas no CDC concretizam mais ainda esses princípios e direitos básicos (NUNES, 2018, p. 121) 
A Política Nacional das Relações de Consumo está prevista nos arts. $4^{\circ}$ e $5^{\circ}$ do CDC. De acordo com Theodoro Junior (2017, p. 23) "o Código, em seus arts. $4^{\circ} \mathrm{e}$ $5^{\circ}$ previu uma Política Nacional das Relações de Consumo, a fim de garantir não apenas a defesa do consumidor, mas, também, estimular uma relação sadia de consumo".

O objetivo da Política Nacional das Relações de Consumo é atender as necessidades dos consumidores, o respeito à sua segurança, dignidade, saúde, assim como a proteção de seus interesses econômicos, a evolução da sua qualidade de vida, e, a transparência e harmonia das relações de consumo. Ademais, Reis Finkelstein e Sacco Neto, (2010, p. 23-24) apontam que,

\footnotetext{
São esses princípios que permitem que se chegue a um entendimento harmônico no que tange às regras aplicáveis. Esse ponto é, sem dúvida, o desenvolvimento da Política Nacional das Relações de Consumo, destacando-se a consagração da hipossuficiência e da vulnerabilidade do consumidor.
}

Neste sentido, Tartuce (2020, p. 21) aduz que "o estudo dos princípios consagrados pelo CDC é um dos pontos de partida para compreensão do sistema adotado pela Lei consumerista como norma protetiva dos vulneráveis negociais". A seguir será apontado e discorrido sobre alguns dos princípios e proteções ao consumidor, quais sejam, princípio da vulnerabilidade, princípio da boa-fé objetiva e princípio da transparência e da informação.

\subsection{PRINCÍPIO DA VULNERABILIDADE}

O princípio da vulnerabilidade se caracteriza pelo reconhecimento de que a parte consumidora é a mais fraca na relação de consumo. Insta salientar que a presunção de vulnerabilidade não admite prova em contrário e é decorrente de lei. (REIS FINKELSTEIN; SACCO NETO, 2010).

É impossível que o sujeito consumerista tenha vasto conhecimento sobre todos os produtos e serviços colocados no mercado. O marketing, publicidade e os vários meios de oferecimento do produto ou serviço estão relacionados a essa vulnerabilidade, uma vez que deixam o consumidor submetido às vantagens atrativas expostas pelos meios de informação e comunicação. Ainda, Sobral Pinto e Nogueira 
(2016, p. 36), afirmam que "[...] a vulnerabilidade é a principal característica do consumidor. Esta pode ocorrer de quatro formas: técnica; jurídica; fática e informal".

\begin{abstract}
Não se questiona que o consumidor é a parte mais fraca da relação de consumo, seja porque não tem qualquer controle sobre a produção ou o mercado, seja porque, na maioria das vezes, não possui conhecimentos técnicos e específicos acerca dos bens colocados a sua disposição. Essa vulnerabilidade que, segundo já salientamos, justifica a elaboração de um Código para a proteção do consumidor, nas relações travadas com os fornecedores (THEODORO JUNIOR, 2017, p. 28).
\end{abstract}

Ademais, conforme Nunes (2015) aborda, o sujeito vulnerável é a parte mais fraca da relação de consumo, e isto decorre das questões técnicas e econômicas que o consumidor não tem domínio, e isso faz com que este seja mais frágil com relação ao fornecedor. Outrossim, Reis Finkelstein e Sacco Neto (2010) aduzem que o princípio da vulnerabilidade emana do fato de o fornecedor dominar todo e qualquer método de manufatura ou produção do produto ou serviço, métodos estes que são completamente desconhecidos pelo consumidor, além disso, normalmente, o fornecedor possui um domínio financeiro manifestamente superior ao do consumidor.

Posto isso, Nunes (2015, p. 203) ressalta que "o importante mesmo é saber que a vulnerabilidade é constatação e afirmação legal: basta ser consumidor para ser vulnerável. E, por isso, gozar dos benefícios de proteção instituídos na lei". Claramente, o princípio da vulnerabilidade se origina do fato de o fornecedor dominar os mecanismos de produção do produto ou serviço, que são absolutamente desconhecidos pelo consumidor. Além disso, geralmente, o consumidor detém desvantagem financeira e econômica frente ao fornecedor.

\title{
3.2 PRINCÍPIO DA BOA-FÉ OBJETIVA
}

O intuito deste princípio é estabelecer um padrão ético de conduta entre o consumidor e fornecedor nas relações de consumo. Benjamin, Bessa e Marques (2017), afirmam que o CDC impõe o princípio da boa-fé nos métodos comerciais, nos contratos e na publicidade, destarte, pode-se dizer que a boa-fé é o princípio máximo que o Código de Defesa do Consumidor traz. 
O que se busca com a boa-fé objetiva, é um equilíbrio negocial, e, nos moldes da lei consumerista, este equilíbrio deve ser mantido em quaisquer momentos do negócio jurídico (TARTUCE, 2020).

[...] a boa-fé objetiva, que é a que está presente no CDC, pode ser definida, grosso modo, como sendo uma regra de conduta, isto é, o dever das partes de agir conforme certos parâmetros de honestidade e lealdade, a fim de se estabelecer o equilíbrio nas relações de consumo. Não o equilíbrio econômico, como pretendem alguns, mas o equilíbrio das posições contratuais, uma vez que, dentro do complexo de direitos e deveres das partes, em matéria de consumo, como regra, há um desequilíbrio de forças. Daí que, para chegar a um equilíbrio real, o intérprete deve fazer uma análise global do contrato, de uma cláusula em relação às demais. (NUNES, 2018, p. 123-124)

A expressão boa-fé objetiva indicar um dever de conduta entre as partes da relação contratual, com base na lealdade e confiança. Para que haja o cumprimento deste princípio, os consumidores e fornecedores devem cumprir com os deveres principais e anexos, os deveres principais são as obrigações de fazer, de dar e de não fazer, por outro lado os deveres anexos são constituídos pela proteção, cooperação, informação, confiança e lealdade. O desrespeito a qualquer destes deveres provoca inadimplemento da relação contratual (SOBRAL PINTO; NOGUEIRA, 2016).

Tartuce (2020), aduz que a boa-fé é evidenciada pela exigência de uma conduta idônea dos contratantes em todas as fases do negócio jurídico, e que em qualquer esfera negocial, a boa-fé objetiva deve conter incidência em todas as suas fases. Outrossim, com o intuito de estabelecer um equilíbrio nas relações de consumo, as partes subjetivas devem agir com certa regra de conduta, na base da confiança, respeito, bem como lealdade, focando atingir o fim buscado em comum no contrato.

\subsection{PRINCÍPIO DA TRANSPARÊNCIA E DA INFORMAÇÃO}

O princípio da transparência está diretamente ligado ao direito à informação, estes são princípios fundamentais que devem ser prezados para a satisfatória relação de consumo. Segundo Nunes (2015, p. 201) "o princípio da transparência expresso no caput do art. $4^{\circ}$ se traduz na obrigação do fornecedor de dar ao consumidor a oportunidade de conhecer os produtos e serviços que são oferecidos". Ainda, conforme aponta Nunes, (2015), junto ao princípio da transparência, está o dever de 
informar, no qual o fornecedor está obrigado a prestar todas e quaisquer informações acerca do produto e do serviço, de maneira clara e precisa.

Nas palavras de Tartuce (2020), na esfera jurídica, a informação dispõe de dois sentidos, quais sejam, o dever de informar e o direito a ser informado. O dever de informar diz respeito a quem oferece seu produto ou serviço e consequentemente o expõe no mercado, já o direito de ser informado refere-se ao sujeito vulnerável da relação de consumo, ora consumidor.

Theodoro Junior (2017, p. 50), afirma que o dever de informação não é condicionado apenas ao que concerne às especificações do produto:

\footnotetext{
Esse dever de informação clara não se limita às qualificações do produto ou serviço, mas obriga, também, à informação clara quanto ao conteúdo do contrato a ser celebrado, às obrigações que estarão sendo assumidas pelo consumidor, evitando que seja surpreendido por cláusulas abusivas ou que não consiga cumprir.
}

O dever de informar é exigido antes mesmo do início de qualquer relação contratual, assim como a transparência, trata-se de elementos indispensáveis junto ao produto ou serviço. A soma dos princípios compõe dois deveres, porquanto é dever do fornecedor dar completa e integral informação sobre seus produtos e serviços oferecidos e veiculados no mercado de consumo (NUNES, 2018).

Reis Finkelstein, Sacco Neto (2010), aduzem que o princípio da transparência se estende ao dever de informar, dever este que o fornecedor tem perante 0 consumidor quando expõe um produto ou serviço no comércio. $E$ isto diz respeito não apenas às especificações do produto ou serviço em si, mas também quanto à qualidade, riscos, segurança, e demais tantos fatores que possam colocar em ameaça ou perigo a incolumidade psíquica ou física do consumidor ou de quaisquer terceiros que possam ser submetidos a eventuais riscos.

\section{DA VINCULAÇÃO DA OFERTA, INFORMAÇÃO E PUBLICIDADE}

Consoante ao Código de Defesa do Consumidor (1990), toda informação ou publicidade, suficientemente precisa, isto é, clara e objetiva, veiculada por qualquer meio ou forma de comunicação relacionada a produtos e serviços, obriga o fornecedor que a fizer veicular ou ainda que dela se utilizar, integrando o contrato que vier a ser 
celebrado. "Toda oferta relativa a produtos e serviços vincula o fornecedor ofertante, obrigando-o ao cumprimento do que oferecer. Isso é uma decorrência lógica e natural da sociedade de massas que se instalou, e é regra expressada Lei n. 8.078 [...]" (NUNES, 2015, p. 476).

O Código de Defesa do Consumidor, determina expressamente que toda oferta relativa a serviços ou produtos vincula o fornecedor ofertante, porquanto obriga-o ao cumprimento do que oferecer. Em contrapartida, Sobral Pinto e Nogueira (2016), afirmam que nem toda oferta vincula, mas apenas aquela que for suficientemente clara. Um excesso publicitário não obriga o fornecedor, como a publicidade do Red Bull por exemplo, a empresa não será processada por não ter 'dado asas'. À vista disso, oferta suficientemente precisa é aquela que expõe termos claros e está dentro dos padrões praticados no mercado.

O anúncio publicitário não pode faltar com a verdade daquilo que anuncia de forma alguma, quer seja por afirmação, quer por omissão. Nem mesmo manipulando frases, sons e imagens para, de maneira confusa ou ambígua, iludir o destinatário do anúncio (NUNES, 2018, p. 334).

"Neste sentido, a oferta é vinculante para o proponente, que somente poderá se arrepender antes do conteúdo da proposta chegar ao conhecimento da outra parte e revogá-la" (FINKELSTEIN; SACCO NETO, 2010, p. 108). Destarte, caso o fornecedor de produtos ou serviços recusar o cumprimento à oferta, preconiza a lei consumerista que o consumidor poderá alternativamente, exigir o cumprimento forçado da obrigação, nos termos da oferta, apresentação ou publicidade; aceitar outro produto ou prestação de serviço equivalente; rescindir o contrato, com direito à restituição de quantia eventualmente antecipada, monetariamente atualizada, e a perdas e danos (BRASIL, 1990).

A lei oferece ao sujeito vulnerável alternativas para o exercício de seu direito, podendo ele escolher voluntariamente o que Ihe convenha. O consumidor não precisa apresentar qualquer fundamento ou justificativa para escolher uma das hipóteses previstas no CDC (NUNES, 2015).

De todo modo, a informação levada ao consumidor deverá ser veiculada de forma compreensível e clara, por meio adequados a tal fim, observando sempre os princípios de proteção ao consumidor (FINKELSTEIN; SACCO NETO, 2010). 
No que tange a publicidade enganosa e abusiva, o art. $6^{\circ}$, IV da lei consumerista (1990), aduz que é direito do consumidor a proteção contra métodos comerciais coercitivos ou desleais, assim como práticas e cláusulas abusivas ou impostas no fornecimento de produtos e serviços.

\begin{abstract}
A publicidade enganosa é aquela suscetível de induzir o consumidor em erro, em relação à natureza, às características, à qualidade, à quantidade, às propriedades, à origem, ao preço e quaisquer outros dados do produto e serviço. [...] Publicidade abusiva, por sua vez, é aquela discriminatória de qualquer natureza, que incite a violência, explore o medo ou a superstição, se aproveite da deficiência de julgamento e experiência da criança, desrespeite valores ambientais, ou que induza o consumidor a se comportar de forma prejudicial ou perigosa à sua saúde segurança [...] (THEODORO JUNIOR, 2017, p. 54-55).
\end{abstract}

A lei de defesa ao consumidor é manifesta ao afirmar que as cláusulas contratuais serão interpretadas de forma mais favorável ao consumidor. O artigo 51 do CDC, expõe, exemplificativamente, as cláusulas abusivas, indicando que estas são nulas de pleno direito, ou seja, não produzindo efeito nenhum, contudo, o rol trazido pela lei não é exaustivo (REIS FINKELSTEIN; SACCO NETO, 2010).

A proteção contra a publicidade enganosa e abusiva é trazida pelo CDC para que o consumidor, como parte mais vulnerável na relação de consumo, não seja lesionado por fornecedores que vierem a empregar práticas ilícitas na publicidade.

\title{
4.1 DO ERRO CRASSO NO ANÚNCIO
}

Primeiramente, faz-se necessário esclarecer que a expressão 'erro crasso' no dicionário online de português (2020), significa a ação ou consequência de errar, se enganar ou de se equivocar. Posto isso, de acordo com Nunes, (2018), após oferecida a oferta, o fornecedor fica a ela vinculado, e pode o consumidor exigir o seu cumprimento forçado, nos moldes do art. 35 do Código de Defesa do Consumidor, conforme já mencionado, é o fenômeno da vinculação.

Destarte, o consumidor, por ser a parte vulnerável da relação de consumo, tem o CDC para proteger e assegurar seus direitos. Todavia, se porventura o fornecedor, alegar que houve erro grosseiro no valor do anúncio veiculado, pode ele se retratar e ser desobrigado a cumprir a oferta munida de erro? É uma problemática árdua a ser respondida, eis que a própria jurisprudência diverge quanto a essa questão. 
A resposta é não, com uma única exceção: é de aceitar o erro como escusa do cumprimento da oferta, se a mensagem, 'ela própria', deixar patente o erro, pois caso contrário o fornecedor sempre poderia alegar que agiu em erro para negar-se a cumprir a oferta. Elucidemos com dois exemplos: um de erro visível na mensagem e outro não, que inclusive foi julgado pelo Poder Judiciário (NUNES, 2015, p. 479).

No primeiro exemplo, Nunes (2015), considera que uma loja decide realizar uma oferta em seus televisores, sendo o preço normal de cada TV o valor de R $\$$ 600,00 , e a promoção será anunciada em jornal de grande circulação, e será oferecida a venda de 100 televisores pelo preço de $\mathrm{R} \$ 500,00$. Ocorre que, por erro de digitação o anúncio saí errado, por somente $R \$ 5,00$. Neste exemplo, segundo Nunes, pode o fornecedor recusar a oferta, eis que o erro é flagrante, grosseiro. Nesta suposição, é evidente a falha na oferta, divergindo qualquer padrão usual e regular de preço de venda do produto daquele tipo.

Como tem se entendido no plano jurisprudencial, o anúncio, para não vincular o declarante, deve trazer uma patente onerosidade excessiva, uma declaração de valor irrisório em relação ao valor real de mercado, perceptível de plano. Deduz-se, corretamente, que a boa-fé objetiva exigida do fornecedor ou prestador também vale para o consumidor (TARTUCE, 2020, p. 368).

Ainda, de acordo com Nunes (2015), deve ser considerado um segundo exemplo. Trata-se de uma cristaleira adquirida pelo consumidor, o preço foi ajustado em três parcelas iguais de $\mathrm{Cr} \$ 626.000,00$. Contudo, o fornecedor se recusou a entregar a cristaleira, alegando que houve erro na especificação do preço, no orçamento, por parte de seu empregado. Neste caso, não pode prosperar a alegação do fornecedor, nos moldes dos arts. $30 \mathrm{c} / \mathrm{c} 48$ do CDC.

O fundamento, neste segundo exemplo, é que não pode o fornecedor alegar erro na oferta para não cumprir o contrato, ainda que esse eventual erro tenha partido de terceiros. O negócio jurídico foi documentalmente orçado, foi ajustado o preço e forma de pagamento, porquanto a manifestação da fornecedora quanto a aquisição do produto implica na aplicabilidade dos termos do art. 30 do CDC.

Em contrapartida, Benjamin, Bessa e Marques (2017, p. 286), afirmam que o equívoco na publicidade do produto ou serviço é um risco do anunciante, sendo incabível a invocação de erro: 
No caso do anúncio em desarmonia com o querer do anunciante, não se trata de equívoco sobre o bem, mas de equívoco em anúncio sobre o bem. A fratura, pois, não está no bem em si considerado ou na percepção que o anunciante dele tem, mas na maneira e no momento em que ele expõe sua percepção pela via publicitária. Não há equívoco quanto à essência do bem, mas quanto à comunicação que sobre ele é feita, a custo e risco do anunciante. $E$ isso, decididamente, não é erro, já este deve estar diretamente relacionado com o bem e suas características e não com o discurso sobre seus atributos. Inexistindo, pois, fragmentação material, mas simplesmente formal, incabível a invocação de erro.

Neste mesmo sentido, Marques (2016) aborda que a atividade publicitária implica risco profissional àqueles que a exercem, assim como responsabilidade. Desta forma, o fornecedor ofertante deve responder pela divulgação das informações equivocadas, mal realizadas, pelo inadimplemento do contrato, e por atos ilícitos que decorrem da oferta publicitária. Na concepção de Rocha (1994), com o intuito de solucionar as situações em que há divergência entre a vontade do ofertante e a sua própria declaração, existem teorias para análise da questão, tais como a teoria da verdade real, a teoria da declaração, a teoria da responsabilidade e, ainda, a teoria da confiança.

A teoria da vontade baseia-se no entendimento de que as consequências dos contratos devem condizer com às representações mentais das partes, e cabe ao direito intervir e até cancelar as operações em que exista a ausência ou defeito do pressuposto psíquico (ROPPO, 2009). Ainda, conforme este doutrinador, a teoria da vontade passou a dar lugar à teoria da declaração, que por sua vez conferiu maior relevância aos elementos objetivos, identificando-os externamente. Na hipótese de desarmonia entre a vontade do contratante e a sua declaração, ou melhor, entre o elemento subjetivo e o objetivo, o elemento objetivo deve predominar, haja vista que o direito objetiva à proteção daquele que recebe a declaração de vontade, de modo a assegurar a estabilidade e a segurança nas negociações.

De outra parte, Rocha (1994), aborda sobre a teoria da responsabilidade, afirmando que se o anunciante tenha atuado nos limites da boa-fé, não tendo concorrido com dolo ou culpa, poderia haver a possibilidade de anulação do negócio jurídico entre as partes.

Destarte, no tocante a teoria da confiança, Marques (2016), aduz que na hipótese de haver desconformidade entre a vontade interna e o que de fato foi declarado, este prevalecerá, em regra, se, e na proporção em que despertou 
expectativas e a confiança nos indivíduos destinatários da declaração. Roppo (2009), expõe que no decorrer da evolução de estudo sobre o contrato, se conjectura sua objetivação, haja vista que é reduzida a importância da vontade dos que se vinculam juridicamente, ou seja, da circunstância psicológica para a formação do contrato. Amaral Junior afirma que o consumidor "que teve sua escolha determinada pela publicidade, precisa ter a confiança de que a oferta reflete a vontade efetiva do fornecedor" (AMARAL JUNIOR, 1995, p. 50).

Outrossim, ainda sobre a teoria da confiança, Marques (2016) ressalta que, se o destinatário da declaração poderia ter ou tinha conhecimento de modo razoável que não correspondia à vontade interna de quem a declarou, no mesmo instante da declaração, poderá esta ser anulada. Em outras palavras, se quem recebeu a mensagem, agiu de má-fé, não poderá usufruir do equívoco entre a vontade interna e a declaração manifestada da outra parte. Nessa perspectiva, após divulgada a declaração de vontade, se despertada a confiança no consumidor, impossível seria a sua anulação. Contudo, se a declaração não foi capaz de suscitar a confiança no homem médio, seria possível a sua não execução.

Ocorre que, quando a publicidade obviamente contém equívoco, não desperta expectativas legítimas no consumidor, ao passo que não é capaz de suscitar a confiança no homem médio, porquanto, quando a oferta está munida de erro crasso, não é apta a obrigar que o fornecedor cumpra-a na forma veiculada, haja vista que se fosse possível, estaria contrariando a boa-fé objetiva, que deve ser observada tanto pelo consumidor quanto pelo fornecedor, eis que aquele não pode se beneficiar de erro claro do fornecedor ofertante (DIAS, 2013, p. 85).

Em contrapartida, Miranda (2002), ao analisar a formação do contrato, aborda que o declarante não pode conseguir a anulação do negócio por erro após constatar que sua declaração de vontade não foi a mesma manifestada na declaração, com a justificativa de que não se pode prejudicar as legítimas expectativas do consumidor que confiou na validade da declaração manifestada. Atualmente, nota-se que se tornou uma prática frequente o equívoco dos fornecedores em relação aos preços dos produtos ou serviços ofertados, e, à vista disso, torna-se indispensável procurar constatar se o fornecedor realmente cometeu um erro na oferta ou se intencionalmente se equivocou, com o intuito de chamar a atenção do consumidor. 
Conforme será visto a seguir, o posicionamento jurisprudencial sobre o erro crasso tem divergência quanto ao entendimento favorável à pretensão do consumidor. Em algumas situações, entende-se que o fornecedor está obrigado a cumprir a oferta como a qual foi veiculada, independentemente de erro crasso, em contrapartida, em certos casos entende-se que quando o preço divulgado no produto ou serviço for muito inferior do que ofertado usualmente, não vincula o fornecedor, não carecendo este a cumprir à oferta.

\title{
4.2 POSICIONAMENTOS JURISPRUDENCIAIS SOBRE O TEMA
}

Os três primeiros julgados referem-se a decisões favoráveis à pretensão do consumidor, contudo, os três últimos julgados abordam decisões desfavoráveis à pretensão do consumidor. O primeiro julgado a ser analisado será o acórdão $\mathrm{n}^{\circ}$ 0018917-70.2015.8.16.0018, do Tribunal de Justiça do Paraná, cujo relator foi o Juiz Leo Henrique Furtado Araújo, conforme disposto na ementa a seguir:

\begin{abstract}
RECURSO INOMINADO. INDENIZAÇÃO POR DANOS MORAIS E MATERIAIS. SENTENÇA DE PROCEDÊNCIA DO PEDIDO INICIAL E CONDENAÇÃO DA RECLAMADA AO PAGAMENTO DE INDENIZAÇÃO POR DANO MATERIAL NO VALOR DE R\$ 57,00 E R\$ 4.000,00 A TÍTULO DE DANOS MORAIS. INCONFORMISMO DA RECLAMADA. TESES RECURSAIS QUE HOUVE UM ERRO MATERIAL NA CONFECÇÃO DO CARTAZ PELA EMPRESA COLABORADORA, O QUE FOI DEVIDAMENTE INFORMADO E EXPLICADO AO CONSUMIDOR, NÃO OCORRÊNCIA DE DANOS MORAIS, AUSÊNCIA DE RESPONSABILIDADE, QUE NÃO HOUVE DANO MATERIAL E NECESSIDADE DE REDUÇÃO DO INDENIZATÓRIO. TESES NÃO ACOLHIDAS. Quantum relação de consumo. Inversão do ônus probatório. Aquisição de lâmpadas. Produto anunciado em encarte. Cobrança de preço a maior. Não cumprimento da oferta veiculada. Erro grosseiro não configurado. Recusa indevida no cumprimento do ofertado em encarte. Segundo o artigo $30 \mathrm{do} c d c$, a legislação consumerista adotou o princípio da vinculação, segundo o qual o fornecedor que utiliza os meios de comunicação para fazer uma oferta a ela fica vinculado. Nesse sentido, o artigo 35 , I do mesmo instrumento legal, determina que é direito do consumidor, em recusando o fornecedor a cumprir o que publicara, exigir o cumprimento forçado da obrigação nos termos da oferta. [...]. Sentença mantida por seus próprios fundamentos. Recurso conhecido e desprovido. (TJPR - 1 ${ }^{\mathrm{a}}$ Turma Recursal - 0018917-70.2015.8.16.0018 - Maringá - Rel.: Juiz Leo Henrique Furtado Araújo - J. 25.04.2017)
\end{abstract}

$\mathrm{Na}$ situação acima, o consumidor ajuizou ação de indenização por danos materiais e morais em face de um supermercado. Isso se deu por conta do preço de 
lâmpadas led anunciadas no cartaz com o valor de $\mathrm{R} \$ 12,59$ (doze reais e cinquenta e nove centavos).

Diante da oferta, o consumidor decidiu comprar cinco unidades da lâmpada, ocorre que, ao passar as compras no caixa do supermercado, estava sendo cobrado o valor unitário da lâmpada $\mathrm{R}$ \$23,99 (vinte e três e noventa e nove). Ao indagar a diferença de preço cobrada a mais, o fornecedor alegou que a lâmpada em oferta era de menor potência da escolhida pelo consumidor, e por este motivo não era o mesmo preço. Afirmações estas incabíveis, eis que as lâmpadas escolhidas pelo consumidor eram de fato as que foram informadas na oferta. Destarte, o juiz julgou procedente o pedido do autor, ora consumidor, condenando o fornecedor ao pagamento de danos morais e materiais.

O fornecedor opôs recurso, o qual foi conhecido e desprovido, tendo como fundamentação que houve descaso e desrespeito com o consumidor, que teve suas legitimas expectativas frustradas, e que é indevida a recusa no cumprimento do ofertado em encarte, ante ao princípio da vinculação, mantendo a sentença por seus próprios fundamentos.

O segundo julgado faz menção a apelação cível n. 300384951.2009.8.26.0506, do Tribunal de São Paulo, julgado pelo Juiz Luiz Antonio de Godoy, exposto a seguir:

\begin{abstract}
OFERTA. Preço de notebook anunciado com preço inferior ao pretendido pelo anunciante Vinculação da oferta Hipótese em que a retificação do preço, a despeito de ter sido veiculada antes do início do prazo de vigência, não o foi pela mesma forma da oferta (panfleto enviado ao endereço da consumidora), mas por via indireta (jornal) Inteligência do art. 429, parágrafo único, CC/02 - Erro grosseiro não constatado Preço verossímil ao consumidor Alienação do produto determinada, em observância ao art. 30, CDC Ação procedente Recurso desprovido. (TJSP; Apelação Cível 300384951.2009.8.26.0506; Relator (a): Luiz Antonio de Godoy; Órgão Julgador: $1^{\text {a }}$ Câmara de Direito Privado; Foro de Ribeirão Preto - $2^{\mathrm{a}}$. Vara Cível; Data do Julgamento: 29/07/2014; Data de Registro: 30/07/2014)
\end{abstract}

Neste julgado, a autora entrou com ação de obrigação de fazer para determinar que a requerida lhe venda um notebook pelo preço anunciado. Em síntese, a consumidora alega que a oferta do notebook, foi veiculada por meio de panfleto/jornal enviado ao seu endereço, pelo valor de $\mathrm{R} \$ 899,00$ (oitocentos e noventa e nove reais). 
Destarte, a autora foi em busca da empresa anunciante para fazer a compra do produto.

Ocorre que ao tentar realizar a compra do produto pelo preço anunciado, houve recusa da empresa requerida, sob o argumento de que o valor ofertado é muito inferior ao valor de mercado do produto, eis que o valor a ser anunciado deveria ser de $\mathrm{R} \$$ $1.899,00$ (mil oitocentos e noventa e nove reais), constituindo erro grosseiro, bem como aduz que retificou a oferta do notebook, porquanto não poderia cogitar-se a vinculação da oferta.

A ação foi julgada procedente em favor da consumidora, sob justificativa de que a retificação do preço não foi realizada pela mesma via de sua primeira divulgação, ademais, afirma que os consumidores estão acostumados com promoções das grandes empresas, que muitas vezes anunciam ofertas com mais de cinquenta por cento de desconto, porquanto a oferta de $\mathrm{R} \$ 899,00$ não se mostra inverossímil para um notebook. Inconformada, a empresa requerida apresentou recurso, o qual foi conhecido e desprovido, mantida a sentença de primeiro grau por seus fundamentos.

O último julgado favorável a pretensão do consumidor trata-se do acórdão $\mathrm{n}^{\circ}$ 0006696-55.2015.8.16.0018, do Tribunal de Justiça do Paraná, julgado pelo Juiz Leo Henrique Furtado Araújo, conforme segue:

\begin{abstract}
RECURSO INOMINADO. AÇÃO DE OBRIGAÇÃO DE FAZER C/C INDENIZAÇÃO POR DANOS MORAIS E TUTELA ANTECIPADA. PROPAGANDA ENGANOSA. ANÚNCIO DE XBOX POR R\$ 99,00. BOLETO GERADO E PAGO. DATA DE ENTREGA PROGRAMADA. RECLAMADA ALEGOU EXISTENNCIA DE ERRO GROSSEIRO. SENTENÇA DE PROCEDÊNCIA. INSURGÊNCIA RECURSAL DA PARTE RECLAMADA. RELAÇÃO DE CONSUMO. [...] Falha na prestação dos serviços. inteligência do art. 14 do cdc. descaso e desrespeito com o consumidor. compra concluída com a geração do boleto e pagamento. inexistência de erro grosseiro. dano moral configurado. [...]. sentença mantida pelos próprios fundamentos nos termos do art. 46 da lei $n^{\circ}$ 9099/95. recurso conhecido e desprovido. Decidem os Juízes integrantes da Primeira Turma Recursal do Estado do Paraná, por unanimidade de votos, conhecer e negar provimento ao recurso, nos exatos termos deste voto (TJPR - $1^{\text {a }}$ Turma Recursal 0006696-55.2015.8.16.0018 - Maringá - Rel.: Juiz Leo Henrique Furtado Araújo - J. 11.07.2016)
\end{abstract}

Nesse julgado, o autor realizou a compra online de um Xbox pelo valor de $R \$$ 99,00 (noventa e nove reais), valor este constante no site do fornecedor. Contudo, sete dias após o boleto de pagamento ser gerado e pago, a parte requerida cancelou a compra, sob a alegação de existência de erro no preço anunciado, e afirmou que o 
valor correto era de $R \$ 999,00$ (novecentos e noventa e nove reais), porquanto devolveria o valor pago ao consumidor. As alegações do fornecedor não prosperaram, e o juiz condenou o fornecedor ao pagamento de danos morais.

O fornecedor opôs recurso, e the foi negado provimento. O relator entendeu que houve falha na prestação de serviços, bem como descaso e desrespeito com o consumidor, haja vista que a compra foi concluída com a geração do boleto e pagamento, porquanto o dano moral foi configurado, não podendo o fornecedor deixar de cumprir a oferta.

Quanto ao entendimento desfavorável à pretensão do consumidor, a primeira análise será da apelação cível n. 2015.055202-4, do Tribunal de Justiça de Santa Catarina, cujo relator foi o Desembargador Monteiro Rocha, conforme segue:

\begin{abstract}
DIREITO CIVIL E CONSUMIDOR - RESPONSABILIDADE CIVIL OBRIGAÇÃO DE ENTREGAR COISA C/C INDENIZATÓRIA IMPROCEDÊNCIA EM 10 GRAU - INSURGÊNCIA DA AUTORA OBRIGAÇÃO DE ENTREGAR COISA - ATO ILÍCITO - INOCORRÊNCIA ENTREGA DE MERCADORIA NÃO REALIZADA - AQUISIÇÃO DE 3 TELEVISORES DE 40 POLEGADAS - TELEVISOR ANUNCIADO POR R\$ 179,90 - 10\% DO VALOR DO PRODUTO - ERRO GROSSEIRO PRETENSÃO CONTRÁRIA À BOA FÉ - OBRIGAÇÃO AUSENTE RECURSO DESPROVIDO - SENTENÇA MANTIDA. A boa fé é elemento negocial que se exige tanto do fornecedor quanto do consumidor. Tratandose de erro grosseiro, a oferta publicada não vincula o fornecedor de produtos, mormente quando este publicou errata corrigindo o equívoco. (TJSC, Apelação Cível n. 2015.055202-4, da Capital - Continente, rel. Des. Monteiro Rocha, Segunda Câmara de Direito Civil, j. 24-09-2015).
\end{abstract}

No julgado acima, a autora realizou a compra de três televisores 40 polegadas, anunciados no site do fornecedor pelo preço de $\mathrm{R} \$ 179,90$ (cento e setenta e nove reais e noventa centavos) à vista, ou $8 x$ de $R \$ 22,49$ (vinte e dois reais e quarenta e nove centavos) cada. Relata que o pagamento de uma TV foi realizado por meio de boleto bancário e as demais foram adquiridas através de cartão de crédito, alegou, contudo, que os televisores não the foram entregues.

$\mathrm{Na}$ esfera judicial, requereu a condenação da requerida ao pagamento de danos materiais e morais, bem como a entregar os televisores adquiridos. Em sede de contestação, a requerida afirmou que por um erro no sistema, a televisão foi exibida pelo valor de $R \$ 179,99$, quando, em verdade, o preço exposto deveria ter sido $R \$$ $1.799,90$. Ademais, afirma que um dia após o equívoco, corrigiu o problema e publicou uma errata em sua página expondo o problema, que o consumidor tinha ciência de 
que o preço anunciado estava muito abaixo do preço normal do produto, e que os danos suportados pela autora não ultrapassam os dissabores cotidianos.

Em primeiro grau de jurisdição, o magistrado entendeu tratar-se de erro grosseiro, e que a pretensão do autor é contraria a boa-fé, não havendo obrigação do fornecedor em cumprir com a oferta exposta. Inconformada, a parte autora opôs recurso, o qual foi desprovido, sob o argumento de que a boa fé é elemento negocial que se exige tanto do fornecedor quanto do consumidor, mantendo a sentença por seus próprios fundamentos.

Em sequência, será analisado o processo n. 0000655-47.2017.8.07.0020, do Tribunal do Distrito Federal, cujo relator foi o juiz Esdras Neves, conforme teor que segue:

\begin{abstract}
APELAÇÃO CÍVEL. CONSUMIDOR. OFERTA PUBLICITÁRIA. PRINCÍPIO DA VINCULAÇÃO. ERRO GROSSEIRO. BOA-FÉ OBJETIVA. As relações entre consumidor e fornecedor devem ser regidas pela boa-fé de ambas as partes. A oferta de passagem aérea com valor $90 \%$ abaixo do seu preço normal foge da normalidade das promoções realizadas no Brasil. Diante do grosseiro erro no preço das tarifas aéreas a serem oferecidas pelo fornecedor, facilmente perceptível, não é possível ao consumidor se valer de sua vulnerabilidade legal para fazer prevalecer o valor da oferta, sob pena de enriquecimento sem causa.(Acórdão 1084967, 0000655-47.2017.8.07.0020 Res. 65 CNJ, 20171610007236 APC, Relator: ESDRAS NEVES, 6 a TURMA CÍVEL, data de julgamento: 21/3/2018, publicado no DJE: 27/3/2018. Pág.: 391/396)
\end{abstract}

Neste julgado, alega a autora que houve ampla divulgação e publicidade das tarifas promocionais de passagens ofertadas pela requerida do trecho de São Paulo/Brasil até Bangkok/Tailândia pela quantia de US\$139,00, requerendo, portanto, realizar a compra de tais passagens pelo valor ofertado. No entanto, afirmou a requerida que se trata de erro grosseiro de seu sistema, que excluiu um dígito do valor, eis que, a tarifa para o referido trecho é de US\$1.399,00. A parte autora ajuizou ação indenizatória requerendo a condenação da requerida por danos morais.

O juiz de primeiro grau julgou procedente os pedidos da parte autora. Insatisfeita, a requerida opôs recurso de apelação, pleiteando a reforma da sentença para que fossem julgados improcedentes os pedidos iniciais.

O recurso foi conhecido e provido, bem como a sentença de primeiro grau foi reformada, sob o argumento de que diante do grosseiro erro no preço das tarifas aéreas a serem oferecidas pelo fornecedor, facilmente perceptível, não é possível ao 
consumidor se valer de sua vulnerabilidade legal para fazer prevalecer o valor da oferta, sob pena de enriquecimento sem causa.

O terceiro julgado, trata-se de uma apelação cível sob n. 030571522.2015.8.24.0020, do Tribunal de Justiça de Santa Catarina, cujo relator foi o Desembargador Marcus Tulio Sartorato, a seguir exposto:

\begin{abstract}
CONSUMIDOR. AÇÃO DE OBRIGAÇÃO DE FAZER C/C DANOS MORAIS. PRETENDIDA A RESPONSABILIZAÇÃO DA RÉ POR PROPAGANDA ENGANOSA. SENTENÇA DE IMPROCEDÊNCIA. RECURSO DA AUTORA. ANÚNCIO DE VENDA DE VEÍCULO ZERO QUILÔMETRO POR MONTANTE NOTORIAMENTE MUITO ABAIXO DO VALOR DE MERCADO. IMEDIATA RETRATAÇÃO PELO ANUNCIANTE. EXEGESE DOS ARTIGOS 17, 30 E 35 DO CDC. INEXISTÊNCIA DE ABALO MORAL. AUSÊNCIA DE QUALQUER PREJUÍZO À PARTE AUTORA. CONDUTA QUE DE PER SI NÃO CONFIGURA ILÍCITO INDENIZÁVEL. MERO DISSABOR. [...] SENTENÇA MANTIDA. RECURSO DESPROVIDO. 2. O anúncio vincula o fornecedor, consoante disposto nos artigos 30 e 35 do Código de Defesa do Consumidor. O princípio da vinculação deve ser mitigado, porém, sob a ótica dos princípios da boa-fé e da vedação do enriquecimento ilícito. Sendo assim, não há que se falar em vinculação quando o erro na oferta for grosseiro, visivelmente muito abaixo ao praticado no mercado, demonstrando-se contrário ao bom senso. 3. Nesse contexto, não resta configurada a má-fé do fornecedor na publicação de propaganda nitidamente equivocada. A imediata correção dos termos do anúncio corrobora com essa posição. Constatado mero dissabor, afasta-se o pedido de indenização. (TJSC, Apelação Cível n. 0305715-22.2015.8.24.0020, de Criciúma, rel. Des. Marcus Tulio Sartorato, Terceira Câmara de Direito Civil, j. 23-10-2018).
\end{abstract}

Neste julgado a autora ingressou com ação de indenização por publicidade enganosa, em desfavor de uma empresa de veículos. Alega, em suma, que foi induzida a erro diante de anúncio publicitário vinculado em outdoor pela concessionária, que divulgava a venda de veículo Toyota Etios 2015 mediante o pagamento de 60 (sessenta) parcelas de $\mathrm{R} \$ 480,00$ (quatrocentos e oitenta reais), e com IPVA 2015 grátis. Afirma que, ao realizar contato com esta concessionária, foiIhe informada a necessidade de pagamento de uma entrada no valor de $\mathrm{R} \$ 19.975,00$ (dezenove mil, novecentos e setenta e cinco reais), que não constava expressamente na divulgação, bem como que houve erro crasso no valor divulgado, notoriamente muito abaixo do valor de mercado.

$\mathrm{Na}$ contestação, a requerida suscitou equívoco por parte da autora na compreensão das informações contidas na publicidade, uma vez que na propaganda foi afixado asterisco ao final da oferta, remetendo às demais condições de aquisição do veículo. Alegou, então, distorção da realidade factual e má-fé da consumidora. 
Ressaltou que oportunamente foram informadas as devidas condições de preço, esclarecidos todos os questionamentos da autora e que, antes do seu comparecimento ao feirão, havia sido publicada em jornal errata acerca da publicidade.

Em primeiro grau de jurisdição, a demanda foi julgada improcedente, em desfavor da parte autora. Descontente, a requerente opôs recurso de apelação, pleiteando a reforma da sentença para que fossem julgados procedentes os pedidos iniciais. O recurso foi conhecido e desprovido, sendo mantida a sentença de primeiro grau, sob o argumento de que o princípio da vinculação deve ser mitigado, porém, sob a ótica dos princípios da boa-fé e da vedação do enriquecimento ilícito.

\section{CONSIDERAÇÕES FINAIS}

O tema abordado buscou analisar qual a efetividade do direito do consumidor quanto ao erro crasso no preço de produtos ou serviços. A pesquisa possui notável relevância, tendo em vista que as relações de consumo estão presentes diariamente na vida das pessoas, bem como diante da vulnerabilidade do consumidor.

Ademais, quando o consumidor pretende realizar a compra de um produto ou serviço com valor evidentemente menor que o de costume, ou após a realização de tal compra, Ihe é informado pelo fornecedor que o preço foi exposto com erro crasso, porquanto não poderá adquirir o produto ou serviço da forma como a qual foi publicada, o consumidor sente-se lesado, e vai em busca da tutela jurisdicional para que seu direito de consumo seja efetivado. Neste norte, foi levantado o seguinte problema: quando munida de erro, o consumidor deve ter direito a uma oferta da forma como a qual foi veiculada?

Com o intuito de elucidar a questão, a pesquisa discorreu sobre as relações de consumo, legislação pertinente, bem como os princípios básicos basilares da lei $n$. 8.078/90. Outrossim, foi explanada ampla pesquisa bibliográfica, além da análise de jurisprudências expondo diversos casos com decisões favoráveis e desfavoráveis a pretensão do consumidor.

Pode-se notar que o entendimento predominante é que se a oferta, munida de erro grosseiro, for capaz de despertar a confiança no consumidor naqueles termos divulgados, fica o fornecedor a ela vinculado, no entanto, apesar da vulnerabilidade 
do consumidor, se for concluído que este poderia ter desconfiado da oferta da forma como a qual foi veiculada, não seria possível obrigar o fornecedor à cumprir a oferta nos termos que foi divulgada, porquanto, o princípio da vinculação passa a ser afastado. Neste sentido, após oferecida a oferta, o fornecedor fica a ela vinculado, e pode o consumidor exigir o seu cumprimento da forma como a qual foi publicada. No entanto, quando o preço divulgado do produto ou serviço for muito inferior do que o ofertado usualmente, não vincula o fornecedor, não carecendo este a cumprir à oferta, sob pena de causar enriquecimento ilícito ao consumidor.

O artigo não tem a pretensão de esgotar o tema, haja vista que as próprias decisões dos Tribunais de Justiça divergem quanto a questão, contudo, a pesquisa poderá ser utilizada como referência tanto para o consumidor quanto para o fornecedor, devendo ambos respeitarem os princípios expostos na pesquisa, com o intuito de estabelecer um equilíbrio nas relações de consumo, na base da confiança, boa-fé, bem como lealdade, focando atingir o fim buscado em comum no contrato.

Ressalta-se que a principal função do Código de Defesa do Consumidor baseia-se em limitar as práticas nocivas de mercado, bem como diminuir a vulnerabilidade do consumidor, equiparando as forças dos sujeitos das relações de consumo. À vista disso, salienta-se que o consumidor deve estar sempre atento às informações e ofertas prestadas pelo fornecedor nos meios publicitários.

Diante do exposto, trata-se de direito de todos, inclusive salvaguardado na Constituição Federal de 1988 e no Código de Defesa do Consumidor, ter a garantia de uma informação coerente, precisa e dotada de clareza em relação a um produto ou serviço que está no mercado de consumo, contudo, para solucionar a pretensão, deve ser analisado o caso em concreto observando as decisões dos Tribunais de Justiça, a doutrina, bem como partindo dos princípios norteadores da lei 8.078/90, com ênfase no princípio da vulnerabilidade e da boa-fé objetiva.

\section{REFERÊNCIAS}

AMARAL JUNIOR, Alberto do. O princípio da vinculação da mensagem publicitária. Revista de Direito do Consumidor, São Paulo, n. 15, p. 41-51, abr./jun. 1995. 
BENJAMIN, Antônio Herman V.; BESSA, Leonardo Roscoe; MARQUES, Claudia Lima. Manual de direito do consumidor. 8. ed. rev., atual. e ampl. São Paulo: Editora Revista dos Tribunais, 2017.

BRASIL. Lei $\mathbf{n}$. 8.078, 11 de setembro de 1990. Dispõe sobre a proteção do consumidor e dá outras providencias. Brasília, 11 de setembro de 1990. Disponível em: http://www.planalto.gov.br/ccivil_03/leis//8078.htm. Acesso

BRASIL. Ministério da Justiça e Segurança Pública. A defesa do consumidor no Brasil. Disponível em: https://www.justica.gov.br/seus-direitos/consumidor/a-defesado-consumidor-no-brasil. Acesso em: 14 mar. 2020.

DIAS, Lucia Ancona Lopez de Magalhães. Publicidade e direito. 2 ed. São Paulo: Revista dos Tribunais, 2013.

DISTRITO FEDERAL, Distrito. Tribunal de Justiça do Distrito Federal. Acórdão n. 0000655-47.2017.8.07.0020. Sexta Turma Cível. Relator: juiz Esdras Neves. 27 mar. 2018. Disponível em: https://www.tjdft.jus.br/. Acesso em: 15 jun. 2020.

ERRO CRASSO. In: Dicionário online de português. Disponível em: https://www.dicio.com.br/pesquisa.php?q=erro+crasso. Acesso em: 14 mar. 2020.

FINKELSTEIN, Maria Eugênia Reis; SACCO NETO, Fernando. Manual de direito do consumidor. Rio de Janeiro: Elsevier, 2010. E-book

KHOURI, Paulo Roberto Roque Antonio. Direito do consumidor: contratos, responsabilidade civil e defesa do consumidor em juízo. 4. ed. São Paulo: Atlas, 2009.

MARQUES, Cláudia Lima. Contratos no Código de Defesa do Consumidor: o novo regime das relações contratuais. 8.ed. rev. atual. e ampl. São Paulo: Revista dos Tribunais, 2016.

MIRANDA, Custodio da Piedade Ulbaldino. Contrato de adesão. São Paulo: Atlas, 2002.

NEVES, Daniel Amorim Assumpção. TARTUCE, Flávio. Manual de direito do consumidor: direito material e processual, volume único. 9. ed. Rio de Janeiro: Forense; São Paulo: Método, 2020. E-book.

NOGUEIRA, Gustavo Santana; PINTO, Cristiano Vieira Sobral. Direito do consumidor para concursos. 2. ed. São Paulo: Saraiva, 2016. E-book

NUNES, Rizzatto. Comentários ao código de defesa do consumidor. 8. ed. rev., atual. e ampl. São Paulo: Saraiva, 2015.

NUNES, Rizzatto. Curso de direito do consumidor. 12.ed. São Paulo: Saraiva Educação, 2018. E-book. 
PAIVA, Clarissa Teixeira. O que caracteriza uma relação de consumo. Jus, 01 nov. 2014. Disponível em: https://jus.com.br/artigos/34128/o-que-caracteriza-umarelacao-de-consumo. Acesso em: 14 mar. 2020.

PARANÁ. Tribunal de Justiça do Estado do Paraná. Acórdão n. 0006696-

55.2015.8.16.0018. Primeira Turma Recursal. Relator: Juiz Leo Henrique Furtado Araújo. Maringá, 11 jul. 2016. Disponível em: https://www.tjpr.jus.br/. Acesso em: 15 jun. 2020.

PARANÁ. Tribunal de Justiça do Estado do Paraná. Acórdão n. 0018917 -

70.2015.8.16.0018. Primeira Turma Recursal. Relator: Juiz Leo Henrique Furtado

Araújo. Maringá, 25 abr. 2017. Disponível em: https://www.tjpr.jus.br/. Acesso em: 15 jun. 2020.

ROCHA. Silvio Luis Ferreira da. Erro da oferta no Código de Defesa do Consumidor, Revista Direito do Consumidor, São Paulo, v. 9, p. 58-62, 1994.

ROPPO, Enzo. O contrato. Lisboa: Almedina, 2009.

SANTA CATARINA. Tribunal de Justiça do Estado de Santa Catarina. Apelação Cível n. 2015.055202-4. Segunda Câmara de Direito Civil. Relator: Desembargador Monteiro Rocha. Capital, 24 set. 2015. Disponível em: https://www.tjsc.jus.br/. Acesso em: 15 jun. 2020.

SANTA CATARINA. Tribunal de Justiça do Estado de Santa Catarina. Apelação Cível n. 0305715-22.2015.8.24.0020. Terceira Câmara de Direito Civil. Relator: Desembargador Marcus Tulio Sartorato. Criciúma, 23 out. 2018. Disponível em: https://www.tjsc.jus.br/. Acesso em: 15 jun. 2020.

SÃO PAULO. Tribunal de Justiça do Estado de São Paulo. Apelação Cível n. 3003849-51.2009.8.26.0506. Primeira Câmara de Direito privado. Relator: Juiz Luiz Antonio de Godoy. Ribeirão Preto, 30 jul. 2014. Disponível em:

http://www.tjsp.jus.br/. Acesso em: 15 jun. 2020.

THEODORO JUNIOR, Humberto. Direitos do consumidor. 9. ed. ref. rev. e atual. Rio de Janeiro: Forense, 2017.

Artigo recebido em: 01/10/2020

Artigo aceito em: 23/11/2020

Artigo publicado em: 29/07/2021 